\title{
TECHNIQUES OF INTESTINAL TRANSPLANTATION IN RAT
}

\author{
MARIA FRANCELINA S.C. LOPES, M.D., MSC., ${ }^{\text {* }}$ \\ DANIEL J.F. CARTUCHO, M.D. ${ }^{1}$ \\ ANTÓNIO M.S. CABRITA, M.D., Ph.D., ${ }^{2}$ and \\ JOÃO A.B. PATRÍCIO, M.D., Ph.D. ${ }^{1}$
}

Two surgical models of intestinal transplantation in the rat are described. One is the implantation of fetal and newborn intestine as free grafts into the omentum of adult recipients, the other the adult intestine transplantation as an accessory graft using vascular anastomoses. A hundred and sixteen smallbowel transplantations were done; 36 of which were fetal intestine (group I), 40 of newborn intestine (group II), and 40 of adult intestine (group III). In the fetal and newborn intestinal transplantation, we emphasize the practices that allowed us to avoid ischemic and traumatic injury to the graft. In the adult intestine transplantation with vascular anastomoses, we heighten the modifications in the surgical technique that made the operation easier and the strategies used to prevent hypothermia and hypovolemic shock. Once experienced with the two chosen surgical techniques, transplantation using an avascular segment became much easier and quicker than transplantation with vascular anastomoses.
Os autores descrevem dois modelos cirúrgicos de transplantação intestinal no rato. Um corresponde à implantação de intestino de feto e de intestino de recém-nascido, como enxertos livres, no epíploon de receptores adultos, e o outro corresponde à transplantação de intestino de adulto, como enxerto acessório, usando anastomoses vasculares. Fizémos 116 transplantações intestinais: 36 de intestino fetal (grupo I), 40 de intestino de recém-nascido (grupo II) e 40 de intestino de adulto (grupo III). Realçámos os métodos utilizados para evitar a isquémia e a lesão traumática do enxerto, nas transplantações de intestino de feto e de recém-nascido. $\mathrm{Na}$ transplantação de intestino de adulto com anastomoses vasculares, enfatizámos as modificações na técnica cirúrgica, que facilitaram a operação, e as estratégias usadas para evitar a hipotermia e o choque hipovolémico. Após a familiarização com os dois modelos cirúrgicos, a transplantação intestinal como enxerto avascular revelou-se de execução mais simples e mais rápida do que a transplantação intestinal com realização de anastomoses vasculares.

(c) 1998 Wiley-Liss, Inc.

MICROSURGERY 18:424-429 1998
Nowadays, the laboratory rat (Rattus norvegicus) is one of the most popular models for intestinal transplantation. Its use started with Monchick and Russell's work ${ }^{1,2}$ in the 1970s, in which they applied the surgical techniques with vascular anastomoses, previously developed in bigger models by other investigators..$^{3,4}$ The intestinal transplantation technique varies according to the kind of graft and the investigation. While studying immunogenicity of fetal, newborn, and adult jejunal allografts in the rat, the authors used two methods of small-bowel transplantation. Fetal and newborn grafts were implanted as an avascular segment into the omentum of adult recipients. Adult allograft was transplanted to an adult recipient as a heterotopic accessory graft using aorta-aorta and porto-caval anastomoses. ${ }^{5}$ The aim of

\footnotetext{
${ }^{1}$ Laboratory of Experimental Research, University Hospital of Coimbra, Coimbra, Portugal

Laboratory of Experimental Pathology, University of Coimbra School of Medicine, Coimbra, Portugal

${ }^{*}$ Correspondence to: Dr. Maria Francelina de Sousa Cruz Lopes, Department of Surgery, Hospital Pediátrico de Coimbra, 3000 Coimbra, Portugal.

this study is to review the intestinal transplantation techniques in the rat and to point out the difficulties of the two methods used.

\section{MATERIALS AND METHODS}

\section{Animals}

Wistar and Sprague-Dawley rats were used. Donor rats were Wistar: 19-day-gestation fetuses, 1- or 2-day-old newborns, and 6-10-week-old adults (weighing an average of $330 \pm 51$ g). Recipients were Wistar or Sprague-Dawley adult rats, weighing an average of $250 \pm 70 \mathrm{~g}$.

\section{Experimental Groups}

A hundred and sixteen small-bowel transplantations were done: 36 of fetal intestine (group I), 40 of newborn intestine (group II), and 40 of adult intestine (group III). These grafts were transplanted into Wistar recipients (weak genetic barrier) and Sprague-Dawley ones (stronger genetic barrier). These recipients were further divided into three subgroups that received intramuscular (IM) $10 \mathrm{mg} / \mathrm{kg} / \mathrm{day}$ 
Table 1. Experimental Groups

\begin{tabular}{clll}
\hline Cyclosporine (dose) & \multicolumn{1}{c}{ Group I (36) } & \multicolumn{1}{c}{ Group II (40) } & \multicolumn{1}{c}{ Group III (40) } \\
\hline $0 \mathrm{mg} / \mathrm{kg} /$ day & Wistar-Wistar (6) & Wistar-Wistar (10) & Wistar-Wistar (10) \\
& Wistar-S. Dawley (6) & Wistar-S. Dawley (6) & Wistar-S. Dawley (6) \\
$2 \mathrm{mg} / \mathrm{kg} /$ day & Wistar-Wistar (6) & Wistar-Wistar (6) & Wistar-Wistar (6) \\
& Wistar-S. Dawley (6) & Wistar-S. Dawley (6) & Wistar-S. Dawley (6) \\
$10 \mathrm{mg} / \mathrm{kg} /$ day & Wistar-Wistar (6) & Wistar-Wistar (6) & Wistar-Wistar (6) \\
& Wistar-S. Dawley (6) & Wistar-S. Dawley (6) & Wistar-S. Dawley (6) \\
\hline
\end{tabular}

or IM $2 \mathrm{mg} / \mathrm{kg} /$ day of Cyclosporine A for 21 days, beginning on the day of the transplantation, or were left untreated (Table 1).

\section{Operative Conditions}

Rats were housed according to the European Union Welfare and were allowed free access to water and food. All the operative procedures were performed with clean surgical technique and under anesthesia with IM ketamine "cocktail"' (Ketamine 7.7-11 mg/kg + chlorpromazine 3.8$5.8 \mathrm{mg} / \mathrm{kg}$ ). Fetuses and newborns were sacrificed by hypothermia. A surgical microscope (Wild M 650, Leica) was used, as well as microsurgery instruments. A single dose of IM Cefotaxime ( $50 \mathrm{mg} / \mathrm{kg}$ body weight) was administered to all the recipients at the beginning of the surgery procedure.

\section{Small-Bowel Transplantation as a Free Graft}

Jejunal grafts of fetus and newborn rats were implanted as avascular segments into the omentum of adult rats by the method described by Kellnar et al. ${ }^{6}$ with slight modifications.

For transplantation of fetal intestine, male and female Wistar rats were mated during $24 \mathrm{hr}$. On the 12th day after mating, rat pregnancy was verified by abdominal palpation under light ether anesthesia. Cesarean section was programmed on the 19th gestational day; through an uterotomy one fetus was removed at a time.

After sacrificing the fetus or the newborn rat by immersion in iced fluid, the abdomen was opened by a midline incision. Under a surgical microscope the duodenum was gently flushed with $1 \mathrm{ml}$ of cold $\left(4^{\circ} \mathrm{C}\right)$ lactated Ringer's solution and $2 \%$ mannitol, through a fine catheter inserted by gastrotomy in the fetus and by duodentomy in the newborn. The bowel was stripped of its mesentery, tractioning it with a forceps located under the mesenteric border. Four centimeters of jejunum was excised over a paper disk with the same diameter and was stored in a solution of cold $\left(4^{\circ} \mathrm{C}\right)$ Ringer's lactate, $2 \%$ mannitol, and neomycin sulfate (100 $\mathrm{mg} / 100 \mathrm{ml}$ ).

The jejunal graft was implanted, without vascular anastomoses, into the omentum of the host. It was enveloped by this structure and held to it at four distinct points with $7 / 0$ nylon suture.

\section{Transplantation With Vascular Anastomoses}

Jejunal grafts of adult rats were transplanted as an accessory graft in adult recipients of the same age, using porto-cava and aorta-aorta anastomoses. This was performed according to the method used by Zhong et al. ${ }^{7}$ with slight modifications.

Briefly, jejunum was harvested with vessels consisting of the superior mesenteric artery attached to an aortic cuff and the portal vein. The aortic cuff was then anastomosed to the recipient aorta and the donor portal vein was anastomosed to the recipient vena cava. The intestinal stumps of the graft were exteriorized as stomas. The recipient's intestine was left intact.

With the rat properly heated (laid on aluminum foil and surrounded by $40^{\circ} \mathrm{C}$ water bags), $6 \mathrm{ml}$ of lactated Ringer's solution was given intravenously (tail or external jugular vein). The abdomen was opened by a left midline incision. Under a surgical microscope, the small and large intestines were separated and the latter was excised. Early interruption of the distal abdominal aorta was done to maintain an adequate flow to the graft. A segment of aorta containing the superior mesenteric artery was isolated after ligation and division of the left kidney vessels, right renal artery, lumbar arteries, and celiac artery. The portal vein was separated from the pancreas and the afferent veins. Immediately before removing the graft, a fine polyethylene catheter was inserted in the distal abdominal aorta. The graft was then perfused in situ with $3 \mathrm{ml}$ of cold heparinized (50 U of heparin/100 $\mathrm{g}$ of rat weight) lactated Ringer's solution $\left(4^{\circ} \mathrm{C}\right)$. Four centimeters of jejunum, with portal vein divided in bevel near the hepatic hilum, and a long segment of aorta containing the upper mesenteric artery were harvested. The lumen of the graft was flushed with $3-5 \mathrm{ml}$ of cold $\left(4^{\circ} \mathrm{C}\right)$ Ringer's lactate and was stored in the same solution containing $2 \%$ mannitol and neomycin sulfate $(100 \mathrm{mg} / 100$ $\mathrm{ml})$.

Keeping the rat warmed, as was done for the donor, and hydrated with $6 \mathrm{ml}$ of lactated Ringer's solution, given intravenously, the abdomen was opened by a midline incision. Under a surgical microscope, the aorta and the inferior vena cava of the host were mobilized from the surrounding tissues by blunt dissection using cotton swabsticks. The inferior vena cava was clamped with a Satinsky type vascular clamp, below the left renal vessels. An end-to-side anasto- 
mosis was performed between the recipient's vena cava and the graft's portal vein, using continuous 8-0 nylon suture. The clamp was released and the venous anastomosis was lightly compressed with cotton. The same vascular clamp was again placed across the distal recipient's aorta. Then, an end-to-side aorta-aorta anastomosis, using continuous 8-0 nylon suture, was performed between the distal end of the donor's aorta and the recipients', 1 to $2 \mathrm{~cm}$ below the venous anastomosis. Both ends of the graft were exteriorized as stomas. Ten milliliters of warm Ringer's lactate was introduced in the peritoneal cavity before closing. If during the surgery the blood loss was significant ( $2 \mathrm{ml}$ or more), the blood free in the abdominal cavity or the equivalent amount of Ringer's lactate was administered intravenously.

\section{Postoperative Care}

Before returning to a cage in a warm room, the recipients were properly heated under a heating lamp and by hot water bags $\left(40^{\circ} \mathrm{C}\right)$. Rats were allowed free access to water and food.

\section{Assessment of Surgical Procedures}

All the rats were followed daily until death or sacrifice on the 21st postoperative day. Body weight was registered daily. Complete necropsies were made to all animals. The animals dying in the first $48 \mathrm{hr}$ after transplantation were considered technical failures. Assessment of the surgical procedures was based on operative time, technical failures, and mortality.

\section{Morphology of Graft}

A sample of donor's jejunum was harvested, placed in a container and fixed in buffered formaline solution for light microscopy. Fetal and newborn samples were enveloped by porous paper before being put into the container. At necropsy, macroscopic aspect of the graft was registered and biopsy specimens of the transplanted intestine were obtained and fixed in buffered formaline solution for light microscopy. Biopsies were stained with hematoxylin and eosin for evaluation.

\section{Statistical Analysis}

Numerical results are expressed as the mean \pm standard deviation. Statistical significance $(P<0.05)$ was determined using the Student's $t$-test.

\section{RESULTS}

Timing required for the execution of surgery in both donor and recipient was $45 \pm 2.7 \mathrm{~min}$ for the former and 187 \pm 10.4 min for the latter. In groups I and II, survival was $100 \%$. All the recipients recovered from the transplantation surgery uneventfully and regained their preoperative weight
Table 2. Correlation Between Early Mortality and Duration of Vascular Clamp Times (Mean \pm S.D.) in Group III

\begin{tabular}{lcc}
\hline Number of recipients & 15 & 25 \\
Early mortality (\%) & 100 & 0 \\
Duration of clamp time (min) & $56.73 \pm 10.02$ & $40.48 \pm 1.23$ \\
\hline
\end{tabular}

${ }^{a} P<0.05, t$-test for independent samples.

within the first week after the intestine transplantation. The animals looked healthy.

In group III, before the learning curve was attained, a death rate of $100 \%$ (9/40) was noted in the first 48-hr posttransplantation. Later on, the death rate decreased to $19 \%$. Mortality was due to graft necrosis $(83 \%)$ and pancreatitis $(17 \%)$. Of the 25 rats that survived after 48 -hr posttransplantation, two animals died, one on the 5 th and the other on the 16th day, from causes unrelated to the surgical technique (8\%). Duration of clamp time needed to do the vascular anastomoses in the recipients correlated with survival (Table 2). All the rats with a warm ischemia time greater than 45 min died $(P<0.05$, Table 2$)$.

The weight loss after surgery was higher for the animals of group III than for those of groups I and II. Their recovery was slower, without attainment of the pretransplant weight.

In groups I and II, with cyclosporine, the transplanted segment induced the formation of a vascularized pseudomesentery that allowed its survival and growth. Grossly, the neogut had the external appearance of distended bowel. In the recipients without cyclosporine not all grafts were viable; in $66.7 \%$ of the animals of group I and in $62.5 \%$ of group II, there was evolution to fibrosis or complete vanishing of the graft. This regression was higher in the transplantation subgroups with stronger genetic barrier.

Under immunosuppression, the fetal intestinal grafts not only grew but also matured. The typical fetal villi became longer and well developed with the appearance of adult normal intestine. As for newborn intestine graft, it was not possible to observe its maturity (if any) due to the rejection of all grafts.

Adult intestinal grafts (group III) were viable in all recipients that survived after 48-hr posttransplantation. Thirty-six percent of these showed grafts with the aspect of normal intestine, although with a diameter slightly smaller than the native intestine. In $64 \%$ of the cases the graft was transformed in a fibrotic tumor.

\section{DISCUSSION}

Numerous studies have shown that fetal and newborn rat intestines, transplanted into some tissues of an adult syngeneic recipient as free grafts, can become vascularized, grow and mature both morphologically and functionally. $6,8-13$ The same results have been obtained in allogeneic intestinal transplantation under optimal doses of Cyclosporine A or FK 506 (tacrolimus). ${ }^{14-18}$ Our study also confirmed the pos- 
sibility of fetal and newborn intestine transplantation as an avascular graft into the omentum of an adult recipient.

Implantation of small bowel in an omental wrap has resulted in better grafts than its implantation into subcutaneous tissue or renal capsule. ${ }^{1-12}$ Functional integrity of the grafts following later anastomosis to the recipient's intestine was also demonstrated. ${ }^{6,15}$ Winter et al. ${ }^{19}$ demonstrated that human fetal bowel matures when transplanted into a subcutaneous tunnel on the back of athymic nude mice.

In the present study, the fetal and newborn intestine transplantation as free grafts was generally based on other authors' methods. Because methodology was not always the same, we had to make some options. As Kellner et al., ${ }^{6}$ we chose the omentum to implant the fetal intestine, and though without references, we chose the same structure for the implantation of the newborn graft.

Our preference for the jejunal graft was based on three motives. It was the most used segment in other studies. $^{6,10-12}$ It seemed easier to identify than the ileum. In the fetal and newborn intestine, jejunum's diameter was slightly larger than the ileum, which made the surgical technique easier. The length of the graft $(4 \mathrm{~cm})$ was calculated taking as a reference the implantation surface, in such a way that we could put it straight.

Even though we had highly detailed descriptions about the fetal and newborn small-bowel transplantation there were some difficulties in the method's application. Most of these difficulties were easily overcome after some practice with these fragile beings. Other obstacles, resulting from lacunae in some steps of the method, were overcome by the introduction of some innovating solutions.

There was no reference to the way of determining the gestational day of the pregnant rat. Our option, explained in Materials and Methods, resulted from a personal change in classical procedures. The resource to other alternatives that were probably easier, such as the study of a vaginal cytology, was excluded because of lack of material in our laboratory.

For each gestation there is generally a high number of fetuses: 11 to 13 in our experience. In the beginning of the current study we used to remove from the uterus all fetuses simultaneously to harvest the intestinal grafts and only then perform the transplantation. In this stage we lost some grafts because the scheduled preservation time for the study (15 to $30 \mathrm{~min}$ ) was not accomplished. We chose then to remove one fetus at a time, leaving the others viable within the uterine cavities while we performed each of the transplantations.

The fetal intestine is extremely fragile and tears easily during its handling. It cannot be pinched to carry out traction or cannulation. We overcame this inconvenience by touching it as few times as possible. So we performed intestinal flushing through gastrotomy. We removed the in- testinal mesentery, pulling the bowel with a forceps placed under the mesenteric border, never pinching it. We excised $4 \mathrm{~cm}$ of jejunum, putting it over a paper disk with a diameter equal to the length of the required segment.

The fetal intestinal samples for histological study are very small and easily fall through the gaps of the container used for the histological processing. This way we lost some surgical specimens and, to solve this problem, we started to wrap them in paper before placing it within the container.

Free grafts, with a length smaller than $4 \mathrm{~cm}$ can be implanted without cutaneous stomas, but the grafts get a saccate aspect. Hirthler et al. ${ }^{10}$ got less distended neoguts, with better morphological and histological quality, when they exteriorized the graft ends for irrigation procedures in order to evacuate any accumulated secretion. Unfortunately we did not pay attention to this technical detail, like most of the other authors. As a result, in some cases the occurrence of slight villi flattening could not be positively related with graft rejection. This aspect may be simply due to the excessive compression by the accumulated material within the chronic obstructed intestinal lumen.

We could not find in the literature any research about fetal and newborn rat intestine transplantation using vascular anastomoses between the graft and the host. It seems that this procedure is difficult, even with microsurgical technique, due to the extremely small caliber of their vessels.

In contrast to the fetal and newborn intestine, adult intestine lacks angiogenesis ability after implantation as a free graft. For its survival adult intestinal graft needs vascular anastomoses with the host. ${ }^{13}$ The vessels to anastomose depend on the graft location.

In the rat, the arterial and venous anastomoses between the donor upper mesenteric vessels and the recipient ones are executable techniques, despite the small size of the anastomotic ends. ${ }^{20}$ However, most of the investigators prefer to revascularize the graft by aorta-aorta and porto-cava anastomoses. ${ }^{1,7}$ The invoked reasons are technical simplicity, lack of significant changes on the hepatic metabolism, and high survival of the graft. ${ }^{21}$

The intestinal transplantation techniques with the performance of vascular anastomoses are highly described in the literature. The method that supports our work was mostly the one used by Zong et al. ${ }^{7}$ Again, there were difficulties in applying the method, leading us to research for solutions and the introduction of some changes: The modification of some surgical technique steps was advantageous. Slight left median incision laparotomy, instead of a median one used by Zong et al., ${ }^{7}$ made the access to the vein porta region easier.

The simplification of the surgery in the recipient, making the vascular anastomoses without previous extensive dissection of the aorta and cava's bed, enabled us to diminish the risk of vascular perforation and shortened the operative time. Also, the accomplishment of the arterial anasto- 
mosis using the donor's distal end of the aorta, instead of the proximal one, enabled us to increase sufficiently the distance between the two vascular anastomoses. Thus, the tension over the graft and the risk of intestinal torsion around its vessels were reduced.

The lack of practice in microsurgery was the main cause of early mortality. Bergamo et al. ${ }^{22}$ verified that surgical experience is a very important factor to succeed. To reach a postoperative early mortality rate under $20 \%$ it is necessary to have a previous training in vascular anastomoses with microsurgical technique. Good results are dependent on both the perfection and speed of surgery. This last request implies that vascular anastomoses are performed in less than $45 \mathrm{~min}$. At the beginning we had a mortality of $100 \%$ caused by the necrosis of the graft, results that were similar to other authors. ${ }^{22,23}$ After training, we achieved a postoperative survival rate with identical values to those found in the literature. . $22,24,25$ This was due to a better surgical technique, the shortening of the operative times, and the adoption of measures against other factors that, meanwhile, were identified as mortality causes.

Perioperative hypothermia was found to be another important cause of early mortality. We developed some strategies to prevent hypothermia that were applied to both donor and recipient rats. An adequate body temperature was managed by the partial wrapping of the rat in an isolating substance (aluminum foil) and by surrounding it with warm bags. The first device prevented heat loss; the second kept the rat warm.

The water and electrolytic imbalance was another important cause of early mortality. Zong et al., ${ }^{7}$ in a retrospective study about intestinal transplantation in 400 rats, verified that hypovolemic shock was the main cause of death in the first 48-hr postoperation. In our study, this was managed by fluid loss substitution. In the recipient, these losses were estimated by the free blood volume in the peritoneal cavity. They were replaced with the same volume of IV Ringer's lactate or with blood collected from the abdominal cavity.

Even for an experienced surgeon, the intestinal transplantation with vascular anastomoses in the rat is a true challenge. It is a very long surgery, both in the donor and in the recipient. Intestinal transplantation requires not only much technique but also much preparation to prevent the deleterious effects due to the physiopathological changes occurring during this kind of surgery.

The graft can be placed in an heterotopic position as an accessory to the native intestine. In this case, one or both ends are exteriorized by cutaneous stomas. ${ }^{7,24-27}$ This model shows some advantages in studies about the graft's immunological responses because the graft is accessible to biopsy by the enterostomy.

In the orthotopic intestinal transplantation model, the graft is placed in continuity with the native intestine. ${ }^{7,15,20,28}$ It is very useful to study the nutritional com- petence of the transplant. In the past, mortality in this model was superior to mortality in heterotopic intestinal transplantation because it associated both intestinal and vascular anastomoses' complications. ${ }^{29}$ For these reasons, some authors prefer to place the grafts firstly in heterotopic position and later in orthotopic position. ${ }^{18}$ With the improvement of microsurgical techniques and an adequate perioperative hydration, it is possible nowadays to perform orthotopic transplantation in one step with low mortality. ${ }^{7}$ It is possible to do vascular anastomoses without sutures (cuff technique). Some authors use it in the rat for studies that do not require a long survival of the model. ${ }^{30,31}$

In summary, two types of procedures are currently under discussion for intestinal transplantation in the rat. First, procedures for fetal and newborn intestines, in which avascular grafts are placed in an adult recipient. In these cases, the grafts survive because they have potentiality to get vascular connections with the host. Second, procedures for adult intestine, in which vascular anastomoses are performed between graft and recipient. Intestinal transplantation as a free graft was easier and quicker than intestinal transplantation with vascular anastomoses. Even for an experienced surgeon, the intestinal transplantation with vascular anastomoses in the rat is a true challenge. Practice with the different rat models is required to optimize results.

\section{REFERENCES}

1. Schraut WH. Current status of small bowel transplantation. Gastroenterology 1988;94:525-538.

2. Monchik GJ, Russell PS. Transplantation of the small bowel in the rat: technical and immunological considerations. Surgery 1971;70:693702.

3. Lillehei RC, Goott B, Miller FA. The physiological response of the small bowel of the dog to ischemia including prolonged in vitro preservation of the bowel with successful replacement and survival. Ann Surg 1959; 150:543-560.

4. Stauffer UG, Becker M, Hirsig J, Meier HP, Kara O. The risks of small intestinal transplantation for the recipient: experimental results in young minipigs. J Pediatric Surg 1978;13:465-467.

5. Lopes MF. Transplantação intestinal: imunogenicidade dos aloenxertos de jejuno fetal, de recém-nascido e de adulto — estudo no rato. Tese de Mestrado, Faculdade de Medicina da Universidade de Coimbra; 1997. p. 1-182.

6. Kellnar S, Schreiber C, Rattanasouwan T, Trammer A. Fetal intestinal transplantation: a new therapeutic approach in short-bowel syndrome. J Pediatric Surg 1992;27:799-801.

7. Zhong R, Grant D, Sutherland F, et al. Refined technique for intestinal transplantation in the rat. Microsurgery 1991;12:268-274.

8. Leapman SB, Deutsch AA, Grand RJ, Folkman J. Transplantation of fetal intestine: survival and function in a subcutaneous location in adult animals. Ann Surg 1974;179:109-114.

9. Bass BL, Schweitzer EJ, Harmon JW, Tai Y-H, Sjogren R, Kraimer J. Anatomic and physiologic characteristics of transplanted fetal rat intestine. Ann Surg 1984;200:734-741.

10. Hirthler MA, Raschbaum GR, Hsia WC, IIIner HP, Rikert SL, Goldthorn JF. Segmental fetal small-bowel transplant: establishment of continuity with native small bowel in the rat. Transplant Proc 1990; 22:2448.

11. Tisinai K, Shedd F, Harris R, et al. Comparison of growth, neovascu- 
larization, and enzymatic function of fetal intestinal grafts in the omentum and renal capsule. J Pediatric Surg 1990;25:914-916.

12. Jones S, Sonnino RE, Laberge J-M, et al. Comparison of omental and subcutaneous implantation after cryopreservation of fetal rat small bowel. Transplant Proc 1990;22:2433-2434.

13. Hung W-T, Fang C-L, Liang C-T. Transplantation of the newborn rat intestine. Transplant Proc 1994;26:1646-1648.

14. Guttman FM, Nguyen LT, Laberge J-M, Nguyen N-V, Seemayer TA, Gibbons L. Fetal rat intestinal transplantation: cryopreservation and cyclosporin A. J Pediatric Surg 1985;20:747-753.

15. Kellnar S, Herkomer S, Bae S, Schumackher U. Allogeneic transplantation of fetal rat intestine: anastomosis to the normal bowel of the host. J Pediatric Surg 1990;25:415-417.

16. Ogasa N, Maeda K, Kakamura K, Itoh H, Schwartz MZ. Successful transplantation of newborn rat intestine as a free graft. Transplant Proc 1992;24:1065-1066.

17. Guvenc BH, Salman T, Surmen E, Savci N, Celik A, Altug T. Accessory enteric nutrition. Transplant Proc 1994;26:1649.

18. Maeda K, Oki K, Nakamura K, Schwartz MZ. Small intestine transplantation: a logical solution for short bowel syndrome? J Pediatric Surg 1988;23:10-15.

19. Winter HS, Hendren RB, Fox CH, et al. Human intestine matures as nude mouse xenograft. Gastroenterology 1991;100:89-98.

20. Tsuchiya H, Nagashima K, Yamagata K. Regeneration of mesenteric lymphatic vessels in a new experimental model of orthotopic intestinal transplantation in rats. J Pediatric Surg 1994;29:912-916.

21. Shaffer D, Diflo T, Love W, Clowes GH, Maki T, Monaco AP. Immunologic and metabolic effects of caval versus portal venous drainage in small transplantation. Surgery 1988;104:518-524.

22. Bergamo C, Baraldini V, Gianotti L, Socci C, Braga M, DiCarlo V. First steps of a new team in small bowel transplantation in rats. Transplant Proc 1994;26:1568.
23. Giele HP, Heel KA, Storrie N, McCauley RD, Hall JC. Warm ischaemia time in a model for small bowel transplantation. Microsurgery 1996;17:438-443.

24. Kirkman RL, Lear PA, Madara JL, Tilney NL. Small intestine transplantation in the rat: immunology and function. Surgery 1984;96:280287.

25. Hatcher PA, Deaton DH, Bollinger RR. Transplantation of the entire small bowel in inbred rats using cyclosporine. Transplantation 1987; 43:478-484.

26. Rosemurgy AS, Schraut WH. Small bowel allografts: sequence of histologic changes in acute and chronic rejection. Am J Surg 1986; 151:470-475.

27. Schmid T, Oberhuber G, Körözsi G, Klima G, Margreiter R. Histologic pattern of small bowel allograft rejection in the rat: mucosal biopsies do not provide sufficient information. Gastroenterology 1989; 96:1529-1532

28. Sonnino RE, Teitelbaum DH, Dunaway DJ, Harmel RP. Small-bowel transplantation permits survival in rats with lethal short-gut syndrome. J Pediatric Surg 1989;24:959-962.

29. Kort WJ, Westbroeck DL, MacDicken I, Lameijer LDF. Orthotopic total small-bowel transplantation in the rat. Eur Surg Res 1973;5:8189.

30. Kobayashi E, Toyama N, Kiyozaki H, et al. Small bowel transplantation for pediatric short bowel syndrome: evaluation of the graft length required for development and the immunologic aspects relating to graft length. J Pediatric Surg 1994;29:1331-1334.

31. Johnsson C, Gannedahl, Scheynius A, Tufveson G. Simultaneous occurrence of rejection and graft-versus-host reaction after allogeneic small bowel transplantation. Transplantation 1995;59:1524-1529. 